\title{
Caderno de Fotografias
}

Texт0: Maria Laura Viveiros de Castro Cavalcanti

Fotografias

BoI Bumbá: Andreás Valentim, Evandro

Teixeira e Lóris Machado

Carnaval: Décio Daniel 


\section{I) Seqüência do Bumbá}

\section{Circularidade e Acúmulo na narrativa nitual}

No Bumbá de Parintins/ Amazonas, um dogan anual superpõe-se ao tema da morte e ressurreição do boi. O Bumbódromo situa-se em uma das extremidades de uma linha imaginária que, originada no porto (foto 1), atravessa a Igreja de Nossa Senhora do Carmo e o cemitério local (foto 2), dividindo a cidade em uma metade leste/ jusante/ azul/ Caprichoso e outra oeste/ montante/ vermelho/ Garantido.

A narrativa ritual procede de modo cumulativo. As tribos, com suas danças coreografadas, preenchem gradualmente a arena (fotos 3 e 4). Sua entrada é intercalada pelo aparecimento de personagens dramáticos como o trio Boi Garantido, Pai Francisco e Mãe Catirina na foto 5 e elementos especiais, como a tribo dos índios Gigantes na foto 6. A narrativa é pontuada por apogeus de intensidade crescente que assinalam o surgimento sempre surpreendente dos principais personagens, tal como na foto $7 \mathrm{e} 8$, respectivamente 0 Boi $\mathrm{G}$ arantido de dentro de um coração girando e o Boi Caprichoso emergindo da Boca de um Mapinguari.

Fotografias de Andreás Valentim, Evandro Teixeira e Lóris Machado.

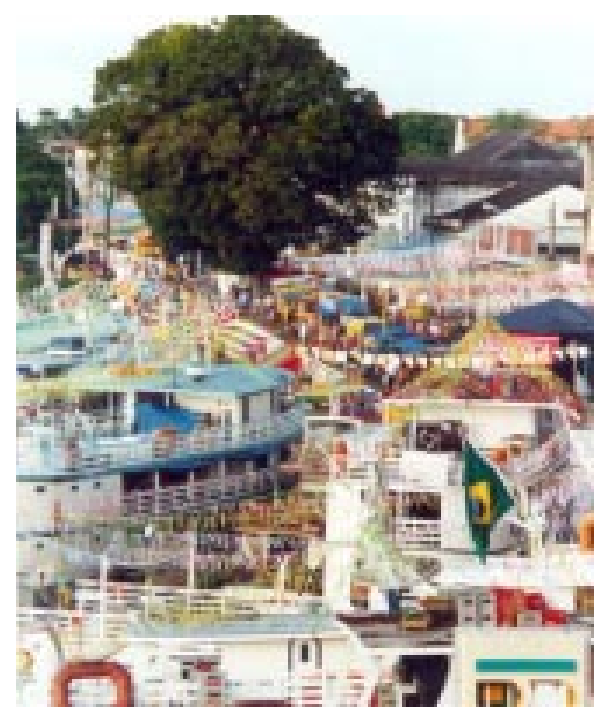



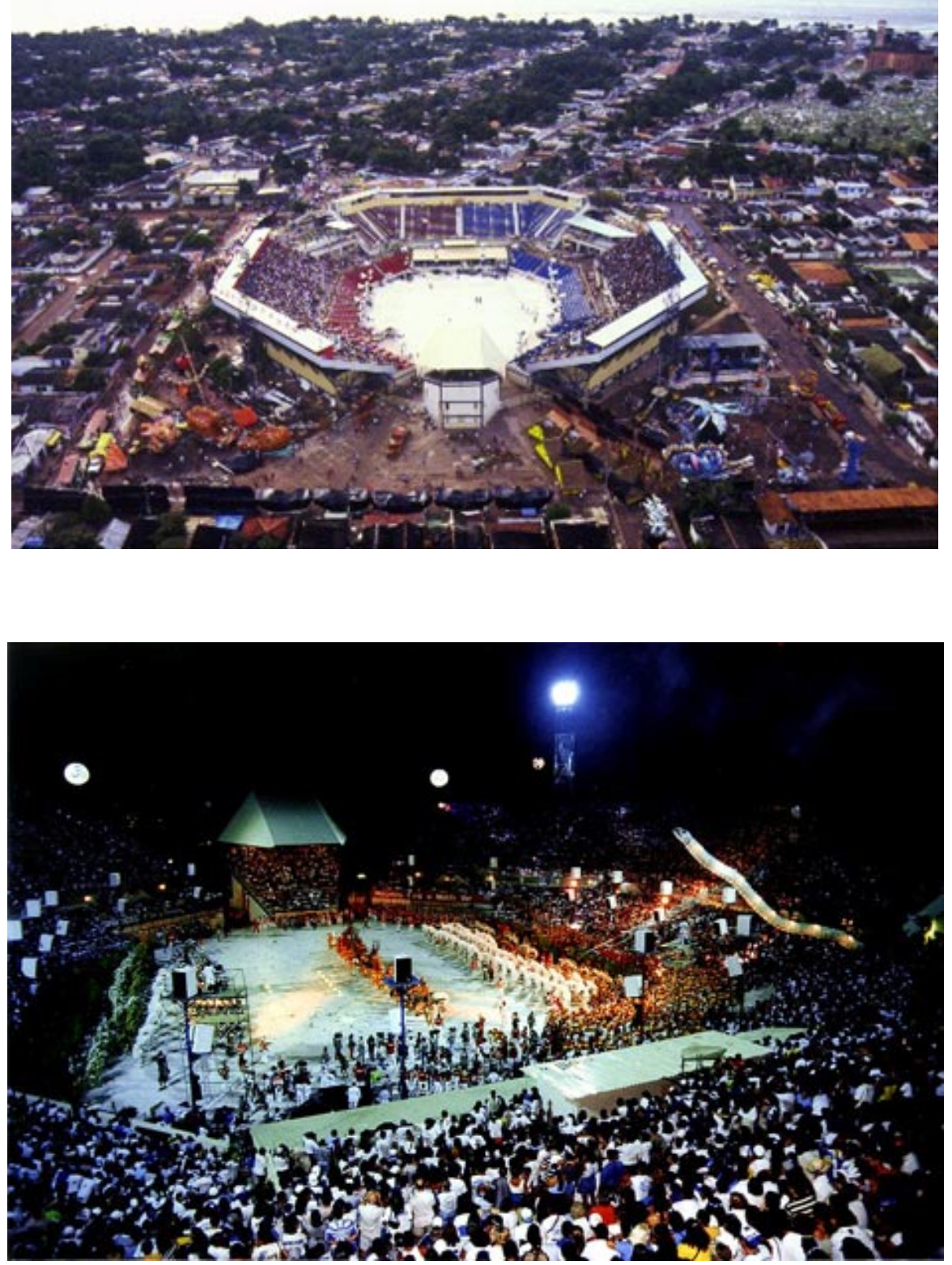

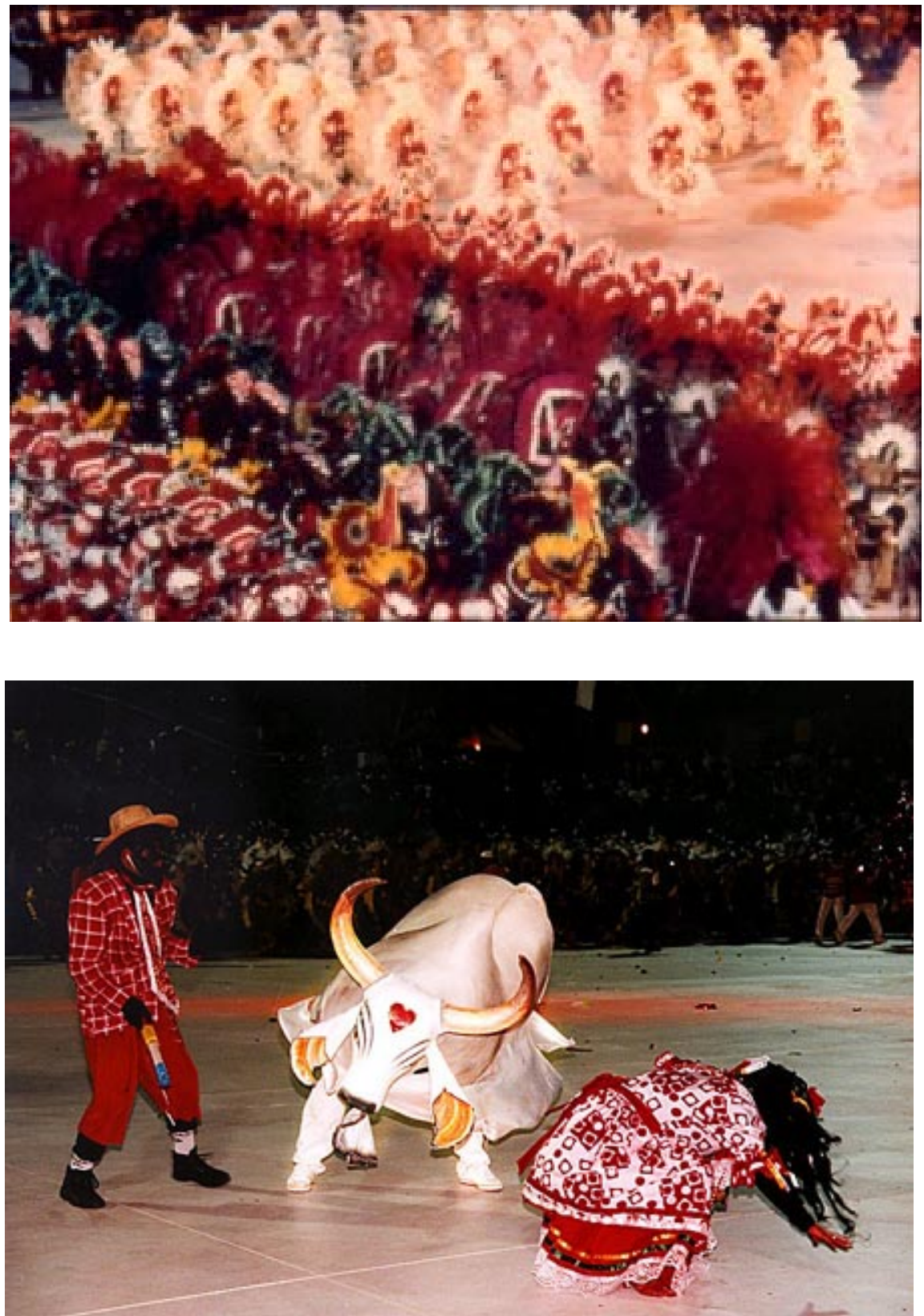

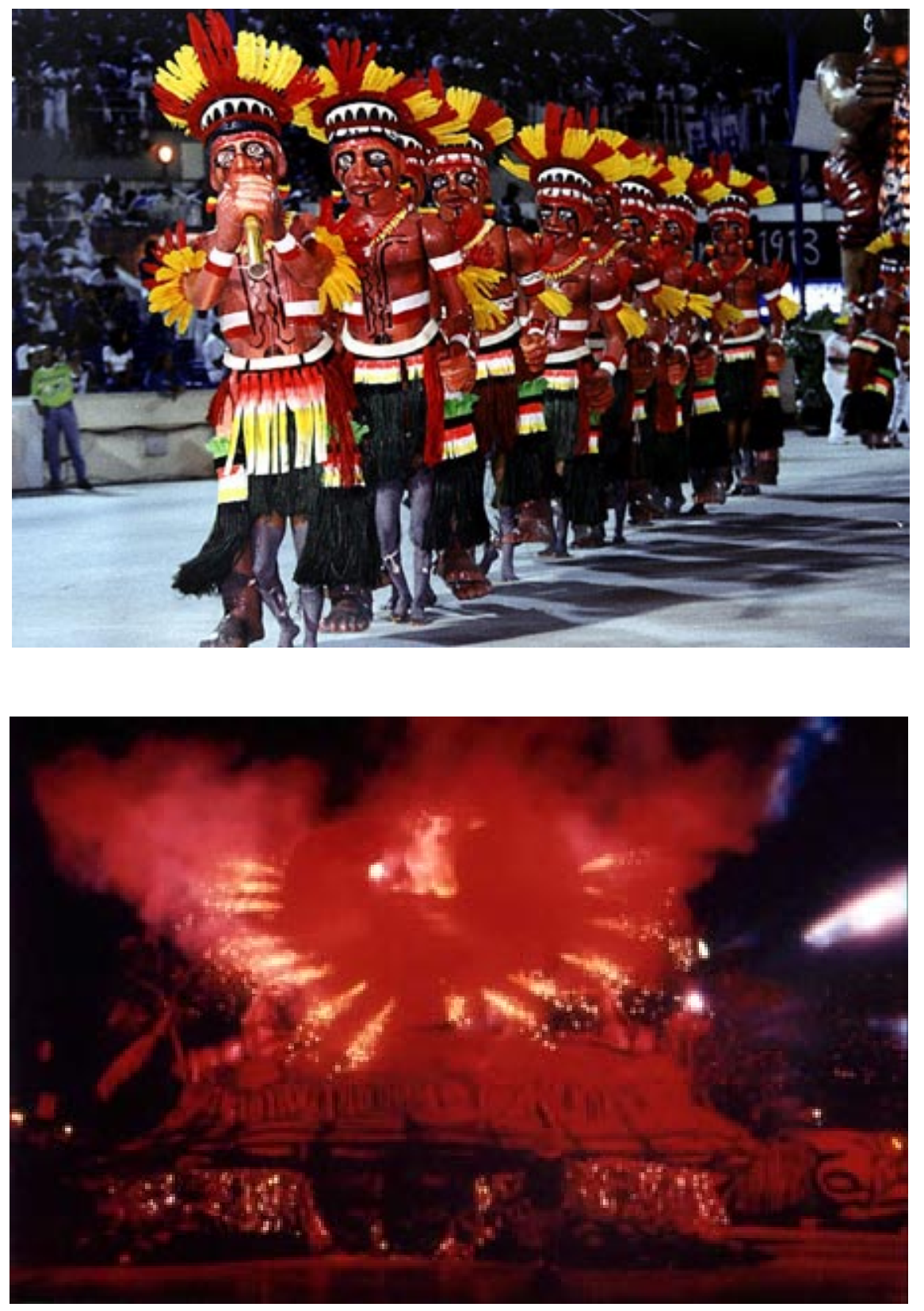


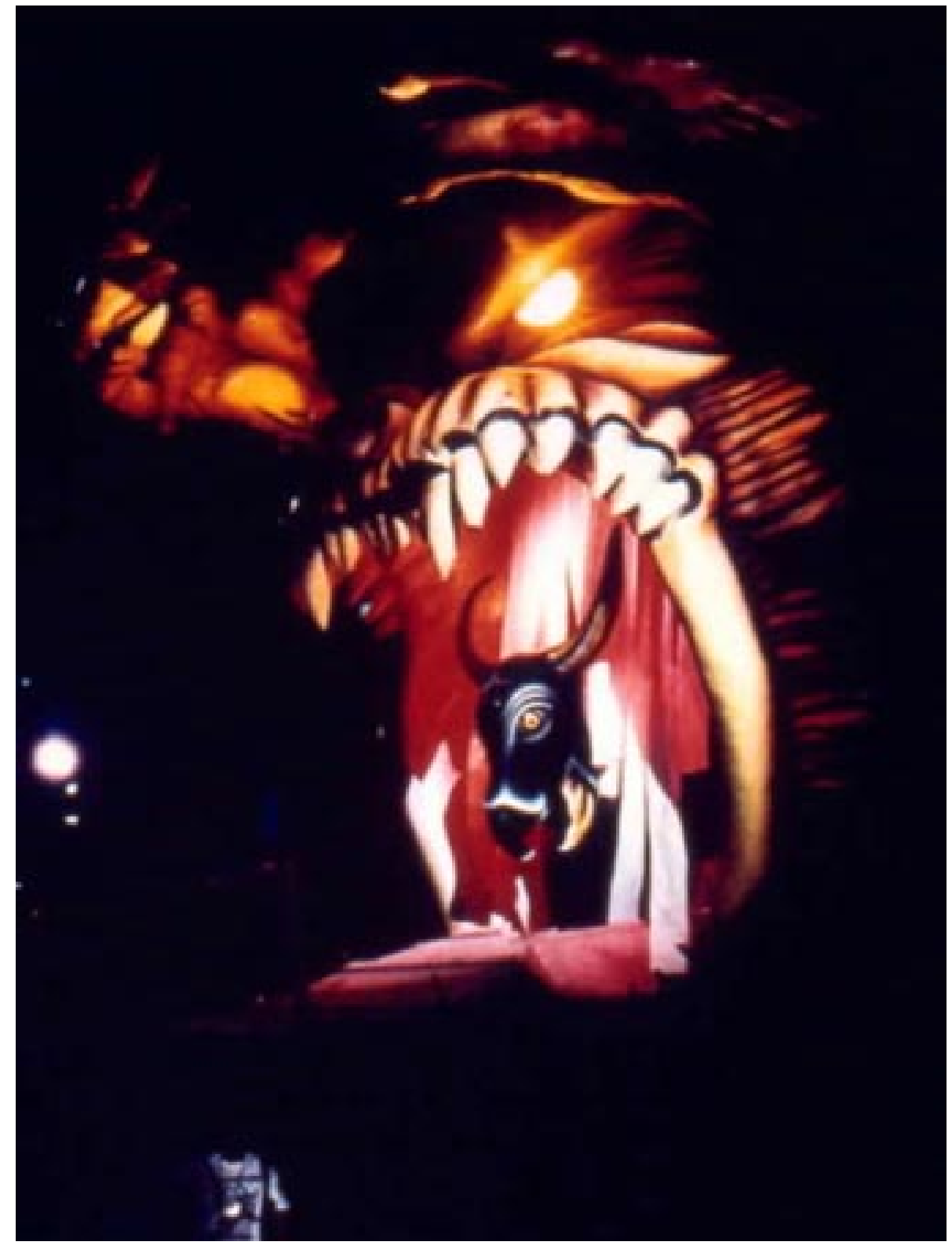




\section{II) Sequência do Carnaval}

\section{Linearidade e passagem na narrativa nitual}

Em um carnaval, a unidade de referência simbólica da narrativa ritual é dada pelo tema do enredo. Na foto 1, a frase mestra - "Sonhar não arsta nada" - do tema do desfile da Mocidade Independente de Padre Miguel em 1992 sai de dentro de uma cabeça tombada no chão do barracão da escola, no início do processo de confecção do desfile. Ao longo desse processo, o enredo desdobrase em sub-temas, elaborados em múltiplas linguagens expressivas.

Um dos diversos sub-temas do "Sonho" era o "Pesadelo Ecológico", representado no carro-alegórico da "Moto-serra destruidora das florestas", aqui registrado na foto 2 - a "Moto-serra" no barracão (observe-se a bricolagem de sua composição plástica) e na foto 3 - a "Moto-serra" no desfile, já acrescida de outros elementos de composição de carro. As alegorias abrem um enredo em muitas cadeias de significados.

O s elementos do desfile então passam em seqüência linear, como o casal de Mestre-Sala e Porta-Bandeira na foto 4, cuja fantasia desenvolve o sub-tema "D elírio Colorido", aludindo aos "sonhos" provocados por alucinógenos.

A foto 5 é a visão frontal da formação linear da escola, aberta pela Comissão de Frente, seguida do Abre-Alas, no desfile de 1992.

Fotografias de Décio Daniel.

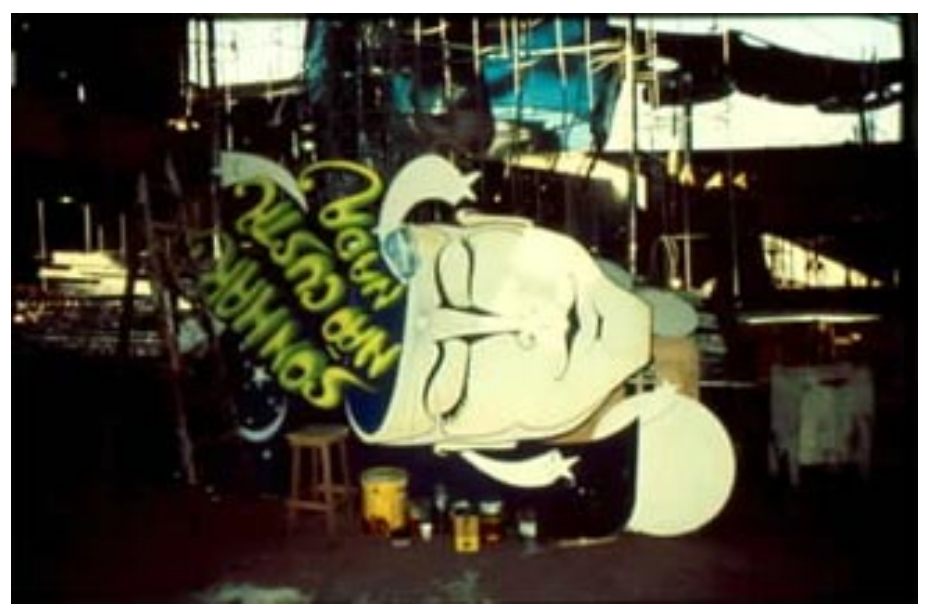



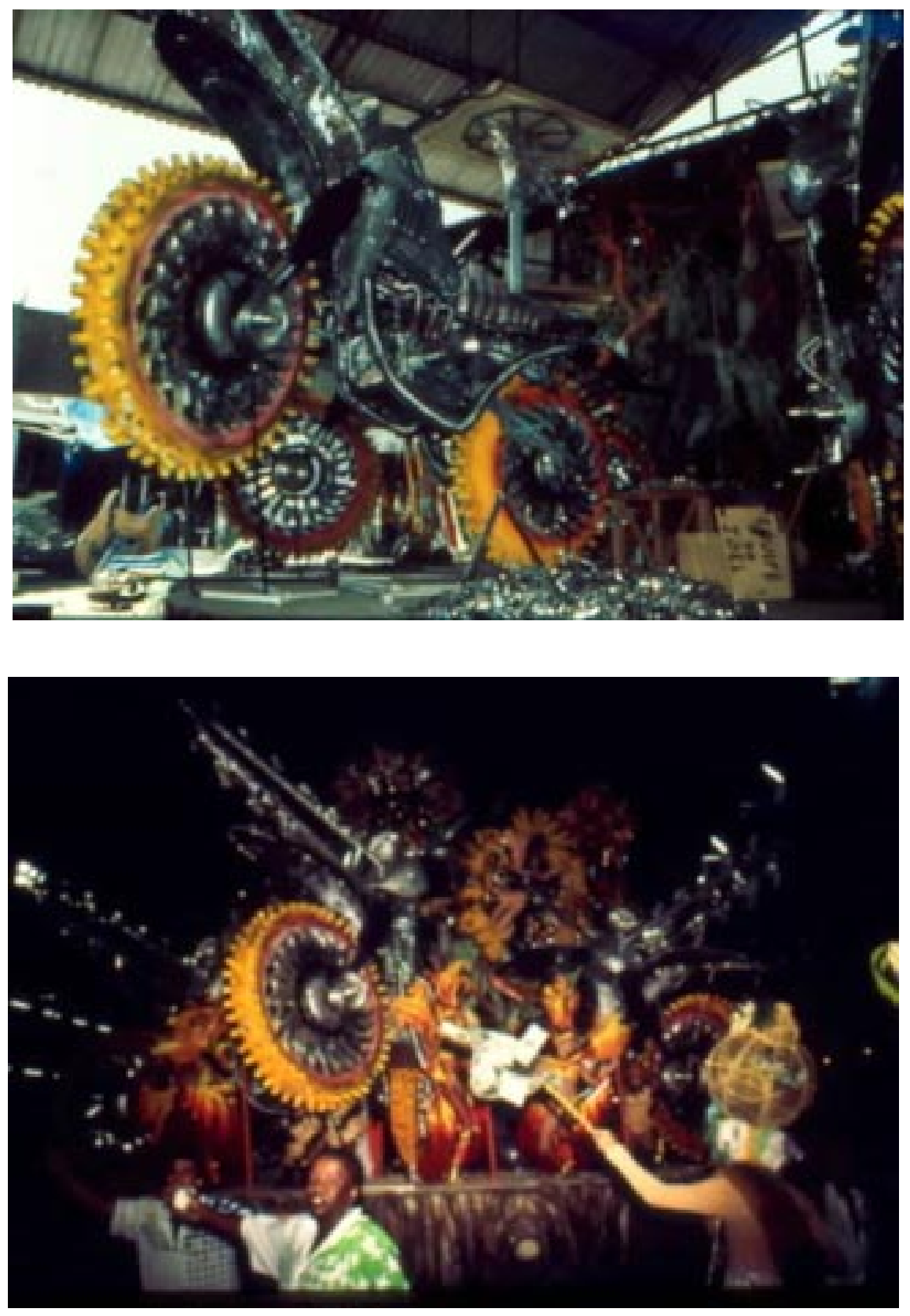

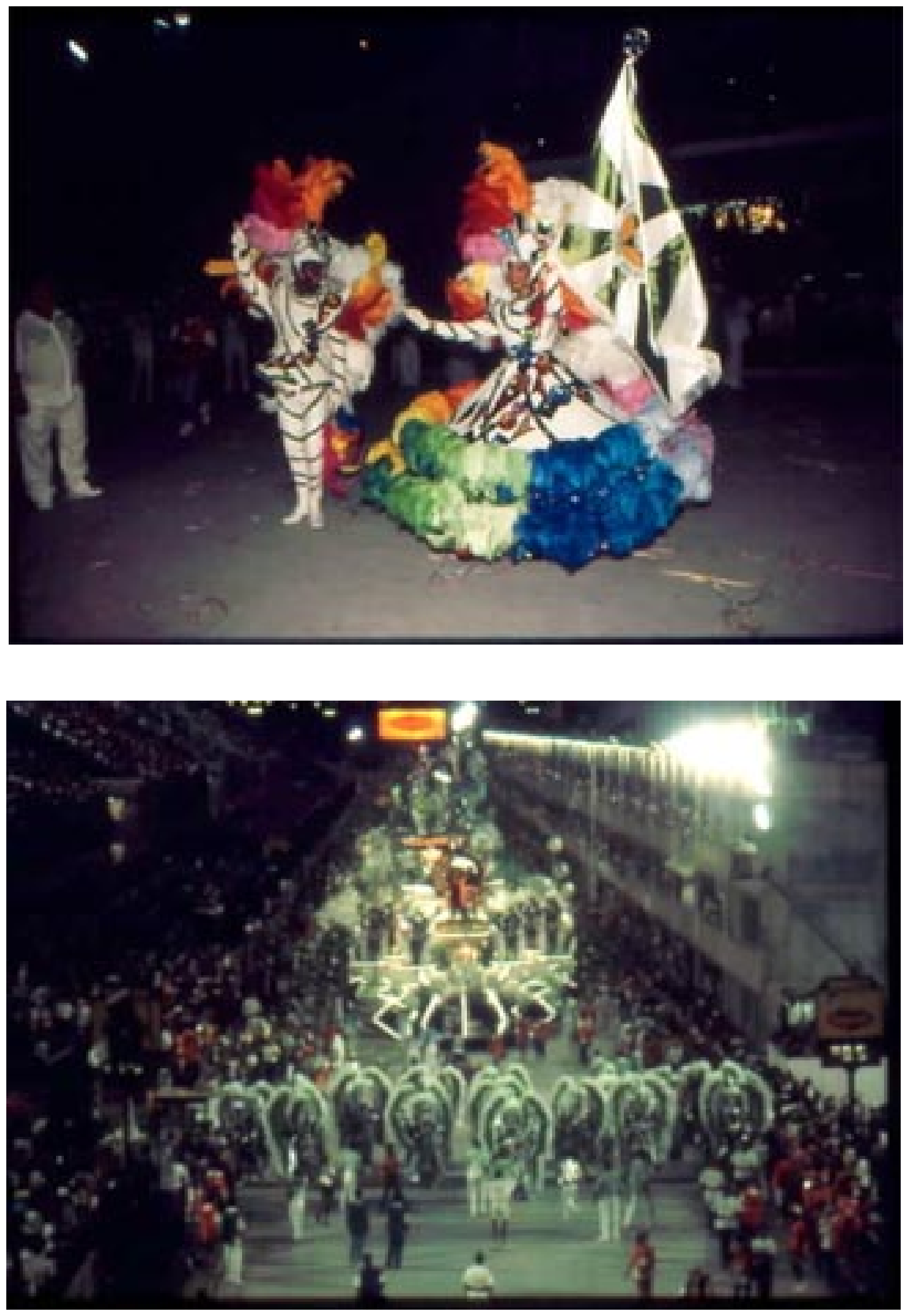